\title{
Nanocomposite Formulation of Ferulic Acid with Different Metals Using Computational Method
}

\author{
Debraj Hazra, Rajat Pal* \\ Department of Microbiology and Biotechnology, Sister Nivedita University \\ DG 1 / 2, New Town, Action area - I, Kolkata - 700156, India \\ *Corresponding author email: rajat.p@snuniv.ac.in
}

Received: 24 June 2020 / Revised: 27 September 2020 / Accepted: 29 September 2020 / Published: 06 October 2020

\begin{abstract}
Formulation of Nanoparticle - drug composite is becoming a growing field of research in today's scientific community. In comparison to the research on the experimental methods for these formulations and their application in various fields, the study of the interaction between drug and nanoparticle is less. In this study, we are reporting about the selection of metals for the formulation of nanocomposite with ferulic acid which is a well-known bioflavonoid having different medicinal activities. Ferulic acid contains only one $-\mathrm{OH}$ group which may reduce the conflict of selecting the metal atom binding site. For our study, we considered twelve metals which have been reported for having the potentiality to synthesis nanoparticles. These metals are gold, silver, copper, iron, zinc, nickel, platinum, palladium, rhodium, ruthenium, cadmium, and antimony. To mimic the actual nanocomposite structure, one metal atom has interacted with two molecules of ferulic acid. All nanocomposite model structures were designed using Avogadro software for windows. It was subjected to energy minimization and $\mathrm{O}$-metal-O bond angle calculation. From the energy levels, it was observed that cadmium exhibited the lowest energy level and antimony showed the highest energy level suggesting their nanocomposite model structures as the most stable and unstable formulation respectively.
\end{abstract}

Keywords: Flavonoids, Ferulic Acid, Nanoparticles, Avogadro Software.

\section{Introduction:}

The vast applications of nanoparticles in various fields have drawn the focus on its research. The area in which nanoparticles have spread to their maximum reach is its study on biomedicine and agriculture. Metals are found to be a very good ingredient for synthesis of nanoparticles. Although few of them have some adverse effect on human health as well as on ecosystem, but adjustment in terms of dosage at which the nanoparticles are used for medical purposes have got very little hazardous effect. Several metals have been reported for being used as a precursor for nanoparticle synthesis, among them, Gold (Au) [1], Silver (Ag) [2,3], Copper (Cu) [4], Iron (Fe) [5], Zinc (Zn) [6], Nickel (Ni) [7], Platinum (Pt) [8], Palladium (Pd) [9], Ruthenium (Ru) [10], Rhodium (Rh) [11], Cadmium (Cd) [12] and Antimony (Sb) [13] are most common. The nanoparticles produced by these metals are widely used as a vehicle for drug molecules to be administered during the treatment. Benefits and supports of such vehicle makes these drug - nanoparticle composites a very useful mode of drug delivery system in medical science. Free drug molecules dissociate and metabolize in the body very easily. But if these drug molecules are administered with a nanoparticle vehicle, the sustained release will occur and the drug will get more time to show its activity. Hence this study of interaction between drug molecule and the nanoparticles have become very useful for researchers who are doing research on drug - nanoparticle composite formulation and their application.

Amongst various Biomolecules having activity in medicinal aspects, flavonoids stand in a strong position. Many flavonoids are using as drugs for treatment against a huge range of diseases. Hence the composite structures of metal nanoparticles with different flavonoid molecules play an important role in the field of biomedical research. Many flavonoid molecules have already been studied for their interaction with metallic 
Nanocomposite Formulation of Ferulic Acid with Different Metals Using Computational Method

nanoparticles. Flavonoid-coated nanoparticle synthesis also serves the purpose where the drug molecules attach on the nanoparticle surface during its formation [14]. Metal nanoparticle synthesis by extracts of different parts of several plants, better known as green synthesis, have also same impact on the research in this field [15].

Here we have chosen ferulic acid as a drug molecule for its major array of applications in various fields. It has some additional antimicrobial [16], anti-inflammatory [17], antioxidant [18], anti-diabetic [19] and anticancer activity [20]. As this bioflavonoid is very much efficient in the field of biomedicine and agriculture, therefore, we used this drug molecule for our research to study interaction pattern of different metal atoms along with the nanoparticles so that we can have a clear idea about the formulations of ferulic acid - metal nanocomposite.

\section{Methodology}

During the synthesis of nanoparticles and their composites, one drug molecule may interact with more than one metal atom. In other words, one metal atom may be bound with more than one drug molecule. Thus, in this study we took into consideration only one metal atom that binds with two identical drug molecules. We know that bioflavonoids are polyphenolic in nature which contains many -OH groups in its chemical structure [21]. To avoid the question that which free $-\mathrm{OH}$ group will act in the interaction of metal atom, we selected ferulic acid (structure of ferulic acid has been shown in Figure 1A) which has only one free $\mathrm{OH}$ group in its molecular structure for its binding with metal atom. As every metal atom which had been reported to interact with two molecules of ferulic acids by free single -OH group present in its structure. Metals we selected here for our study were gold $(\mathrm{Au})$, silver $(\mathrm{Ag})$, copper $(\mathrm{Cu})$, iron $(\mathrm{Fe})$, zinc $(\mathrm{Zn})$, nickel $(\mathrm{Ni})$, platinum $(\mathrm{Pt})$, palladium $(\mathrm{Pd})$, rhodium $(\mathrm{Rh})$, ruthenium $(\mathrm{Ru})$, cadmium $(\mathrm{Cd})$ and antimony $(\mathrm{Sb})$ as these metals have been reported for having capability to synthesize nanoparticles by many research groups. We used Avogadro software for windows [22] to compose the structure of drug nanocomposite. At very beginning we constructed the chemical structure of ferulic acid and allowed it for energy minimization. Afterward we conjugated two ferulic acid molecules with each metal atom separately and the energy minimization was done with the nanocomposite structure for calculating the energy levels of those composites. The energy levels were then listed in tabular form to compare the nanocomposite structures having minimal energy.

\section{Results and Discussions}

Ferulic acid structure was first designed by Avogadro (as shown in Figure 1B) and after energy minimization, this molecule was found to have contained the energy of $125.417 \mathrm{KJ} / \mathrm{Mol}$. This energy minimized structure of ferulic acid was subjected to binding of metal atom at its free-OH group. As it has only one free $-\mathrm{OH}$ group, so there is single metal atom binding site. One metal atom was attached with two free $-\mathrm{OH}$ groups present in two different ferulic acid molecules to form nanocomposite model structure. Likewise, twelve nanocomposite model structures were designed interacting with twelve different metals which have been selected for this study.
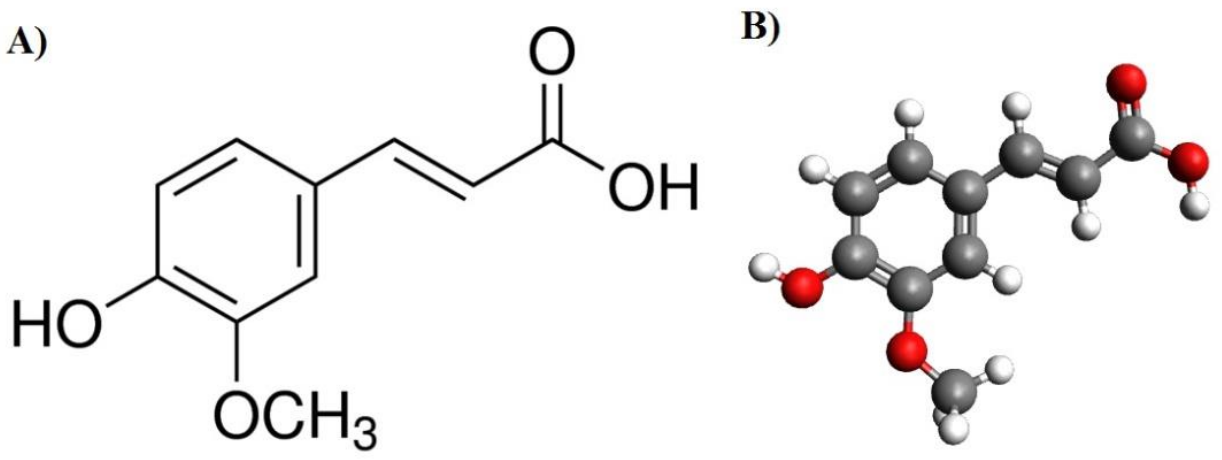

Figure 1: A) Chemical structure of ferulic acid. B) Structure of ferulic acid designed by Avogadro software. 
After minimization of energy for all of these nanocomposite model structures (energy levels of each nanocomposites are listed in table 1), Antimony was found to have highest energy level of $250.359 \mathrm{KJ} / \mathrm{Mol}$ which suggests that the nanocomposite of ferulic acid with this metal (figure 2L) is less stable than other metals. Ferulic acid nanocomposite with silver (figure 2B) and platinum (figure 2G) showed similar energy levels $(205.916 \mathrm{KJ} / \mathrm{Mol}$ and $206.866 \mathrm{KJ} / \mathrm{Mol}$ respectively) with a larger O-metal-O bond angle of $175.2 \AA$ and $177.2 \AA$ respectively. When nanocomposites where formed in association with ferulic acid, Gold (structure shown in figure 2A) and copper (structure shown in figure 2C) also showed almost similar kind energy levels of $204.405 \mathrm{KJ} / \mathrm{Mol}$ and $204.711 \mathrm{KJ} / \mathrm{Mol}$ respectively. In the list of all metal atoms, iron, palladium, rhodium and ruthenium possess energy levels of $202.405 \mathrm{KJ} / \mathrm{Mol}, 202.085 \mathrm{KJ} / \mathrm{Mol}, 202.162$ $\mathrm{KJ} / \mathrm{Mol}$ and $202.262 \mathrm{KJ} / \mathrm{Mol}$ respectively. In figure 2, we have depicted model structures of ferulic acid nanocomposites with iron (figure 2D), palladium (figure $2 \mathrm{H}$ ), rhodium (figure $2 \mathrm{I}$ ) and ruthenium (figure 2J). Ferulic acid nanocomposites with zinc and nickel exhibited energy levels of $201.483 \mathrm{KJ} / \mathrm{Mol}$ and $201.940 \mathrm{KJ} / \mathrm{Mol}$ and their model structures are also shown in figure $2 \mathrm{E}$ and figure $2 \mathrm{~F}$. Cadmium contained lowest energy level of $201.188 \mathrm{KJ} / \mathrm{Mol}$ among all metals considered in this study. The model structure of ferulic acid-cadmium nanocomposite has been presented in figure $2 \mathrm{~K}$. This suggests that cadmium and ferulic acid can form nanocomposite structure with more stability than other metals.

A)

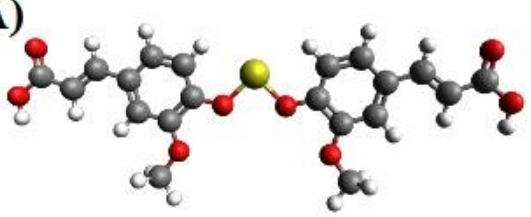

D)

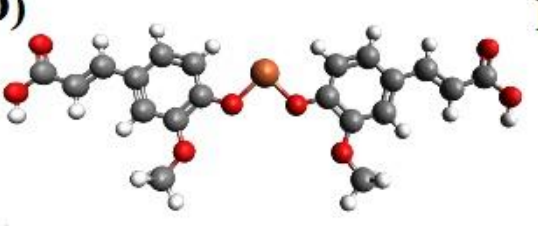

G)

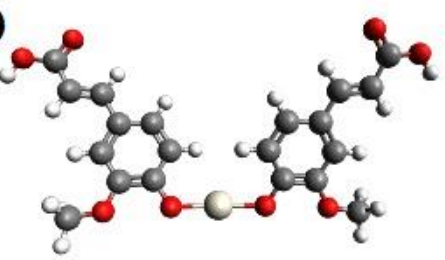

J)

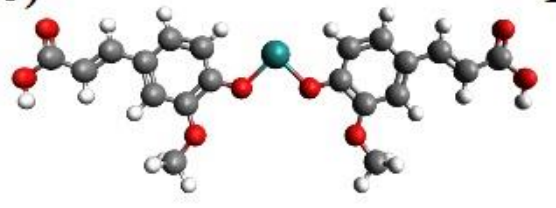

B)

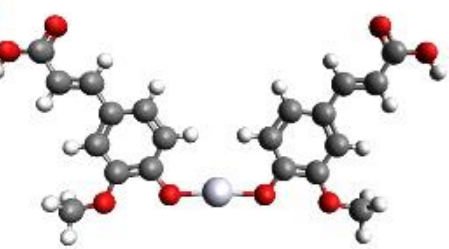

E)

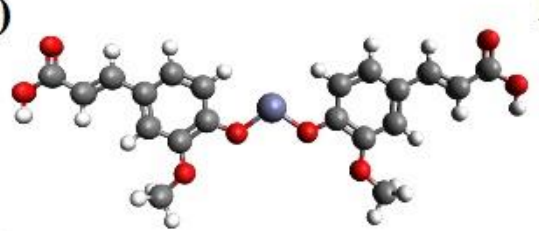

H)

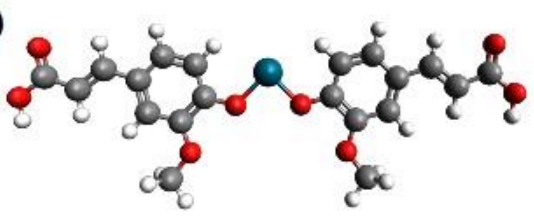

K)

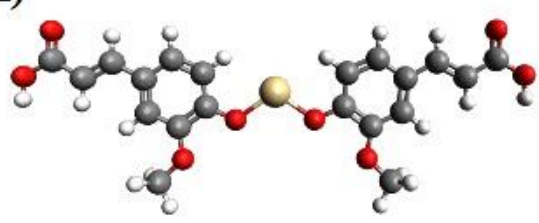

C)

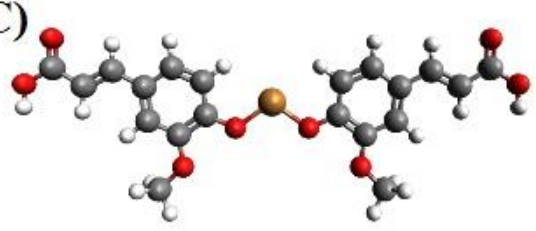

F)

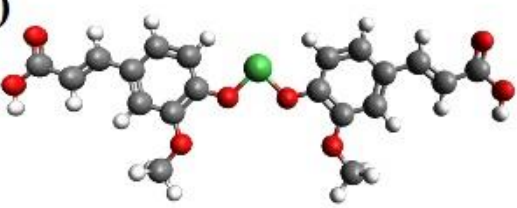

I)

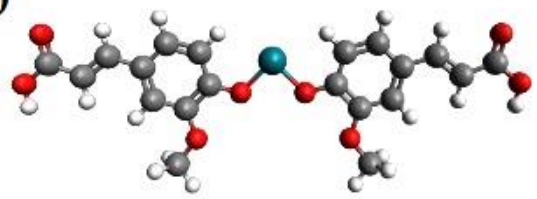

L)

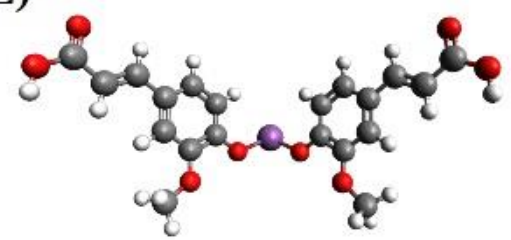

Figure 2: Nanocomposite model structures of ferulic acid with

A) Gold $\left[A u_{-} F\right]$, B) Silver $\left[A g_{-} F\right]$,C) Copper $\left[C u_{-} F\right]$, D) Iron [Fe_F], E) Zinc [Zn_F], F) Nickel [Ni_F],

G) Platinum, $\left.\left[P t_{-} F\right], \mathbf{H}\right)$ Palladium $\left[P d_{-} F\right]$, I) Rhodium $\left[R R_{-} F\right]$, J) Ruthenium $\left[R u_{-} F\right]$,

K) Cadmium [Cd_F] and $\mathbf{L})$ Antimony $\left[S b_{-} F\right]$. 
Nanocomposite Formulation of Ferulic Acid with Different Metals Using Computational Method

Table 1: List of energy levels (KJ/Mol) for different metal - ferulic acid nanocomposites with their $O$-metal-O bond angles.

\begin{tabular}{|c|c|c|c|}
\hline Metal & Compound name & Energy (KJ/Mol) & $\begin{array}{l}\text { O-Metal-O } \quad \text { Bond } \\
\text { Angle (̊) }\end{array}$ \\
\hline Gold & $\overline{A u} \_\mathrm{F}$ & 204.405 & 89.9 \\
\hline Silver & $\overline{\mathrm{Ag} \_\mathrm{F}}$ & 205.916 & 175.2 \\
\hline Copper & $\overline{\mathrm{Cu}} \mathrm{C} \mathrm{F}$ & 204.711 & 109.4 \\
\hline Iron & $\overline{F e \_F}$ & 202.405 & 89.9 \\
\hline Zinc & $\overline{Z n \_F}$ & 201.483 & 109.4 \\
\hline Nickel & Ni_F & 201.940 & 89.9 \\
\hline Platinum & Pt_F & 206.866 & 177.2 \\
\hline Palladium & Pd_F & 202.085 & 89.9 \\
\hline Rhodium & $\mathrm{Rh} \_\mathrm{F}$ & 202.162 & 89.9 \\
\hline Ruthenium & Ru_F & 202.262 & 89.9 \\
\hline Cadmium & Cd_F & 201.188 & 109.4 \\
\hline Antimony & Sb_F & 250.359 & 91.2 \\
\hline
\end{tabular}

The study of interaction between metal atom and flavonoid molecule is very much important because many research groups are working nowadays to formulate these types of nanocomposites. The formation of nanocomplex with ferulic acid and silver nanoparticles has been reported by Wang et al. (2007) [23]. Copper has also been observed for having the potency to form nanocomposite in presence of ferulic acid [24]. The studies of complex formulation of this flavonoid along with iron [25] and zinc [26] have also been done. Although many other groups have been working in the field of metal nanocomposite formation by various experimental approaches, but the study of the interaction between the drug molecule and metal atom has not yet been done extensively. Very few research articles are available on their interaction study. Thus, we discussed that this model may mimic as an actual nanocomposite structure for instance one metal atom binds with two molecules of drug. This study can be related to the nanocomplex structures synthesized by chemical reduction methods in laboratories. Computational and experimental research on the nanoparticle mediated drug delivery system [27] has already been taken an important role in this field. In this respect our work may help the researchers who are now currently engaged in this research area.

\section{Conclusion}

From this present study we can conclude that all these metal atoms used here can be a very good option to formulate nanocomposite structure having varieties of bond angle and a range of energy levels. Amongst all of them, antimony was found to have highest energy in contrast to cadmium that showed the lowest energy level when attached with two molecules of ferulic acid. These finding can draw the conclusion that antimony forms most unstable nanocomposite in comparison to cadmium which forms the most stable nanocomposite formation with ferulic acid. If we put other metal atoms in a series of order starting from unstable to stable, we can find as platinum, silver, copper, gold, Palladium, rhodium, ruthenium, iron, nickel and zinc.

\section{Declarations}

\subsection{Acknowledgements}

We are very much thankful to Dr. Atreyi Ghosh, Dr. Somsubhra Thakur Choudhury, Dr. Fatema Calcuttawala and Dr. Milon Banik for their help and cooperation throughout this study. We are also grateful for receiving the start-up grant from Sister Nivedita University to support this work. 


\subsection{Funding Source}

Sister Nivedita University start up grant.

\subsection{Competing Interests}

The authors declared that no conflict of interest exist in this work.

\section{How to Cite this Article:}

D. Hazra and R. Pal, "Nanocomposite Formulation of Ferulic Acid with Different Metals Using Computational Method", Adv. Nan. Res., vol. 3, no. 1, pp. 40-45, Oct. 2020. https://doi.org/10.21467/anr.3.1.40-45

\section{References}

[1] B. Duncan, C. Kim, and V. M. Rotello, "Gold nanoparticle platforms as drug and biomacromolecule delivery systems", Journal of Controlled Release, vol. 148, no. 1, pp. 122-127, 2010. https://doi.org/10.1016/j.jconrel.2010.06.004

[2] C. A. D. Santos, M. M. Seckler, A. P. Ingle, I. Gupta, S. Galdiero, M. Galdiero, A. Gade and M. Rai, "Silver Nanoparticles: Therapeutical Uses, Toxicity, and Safety Issues", Journal of Pharmaceutical Sciences, vol. 103, no. 7, pp. 1931-1944, May, 2014. DOI: $10.1002 /$ jps. 24001

[3] A. K. Mandal, "Silver Nanoparticles as Drug Delivery Vehicle against Infections", Global Journal of Nanomedicine, vol. 3 no. 2 , pp. 14, Oct. 2017. DOI: 10.19080/GJN.2017.03.555607

[4] T. Kruk, K. Szczepanowicz, J. Stefanska, R. P. Socha and P. Warszynski, "Synthesis and antimicrobial activity of monodisperse copper nanoparticles”, Colloids and Surfaces B: Biointerfaces, $\quad$ vol. 128 (1), pp. 17 - $22 . \quad$ Apr. 2015. https://doi.org/10.1016/j.colsurfb.2015.02.009

[5] S. A. Mahdy, Q. J. Raheed. and P. T. Kalaichelvan, "Antimicrobial Activity of zero-valent Iron Nanoparticles", International Journal of Modern Engineering Research”, vol. 2, no. 1, pp. 578-581, Jan-Feb. 2012.

[6] S. Rojas, F. J. Carmona, C. R. Maldonado, P. Horcajada, T. Hidalgo, C. Serre, J. A. R. Navarro and E. Barea, "Nanoscaled Zinc Pyrazolate Metal-Organic Frameworks as Drug-Delivery Systems", Inorganic Chemistry, vol. 55, no. 5, pp. 2650-2663, Feb. 2016. DOI: https://doi.org/10.1021/acs.inorgchem.6b00045

[7] D. Guo, C. Wu, J. Li, A. Guo, Q. Li, H. Jiang, B. Chen and X. Wang "Synergistic Effect of Functionalized Nickel Nanoparticles and Quercetin on Inhibition of the SMMC-7721 Cells Proliferation", Nanoscale Research Letters, vol. 4, Aug. 2009. DOI: https://doi.org/10.1007/s11671-009-9411-x

[8] J. Kim, T. Shirasawa and Y. Miyamoto, "The effect of TAT conjugated platinum nanoparticles on lifespan in a nematode Caenorhabditis elegans model", Biomaterials, vol. 31, no. 22, pp. 5849-5854, Aug. 2010. DOI: https://doi.org/10.1016/j.biomaterials.2010.03.077.

[9] C. P. Adams, K. A. Walker, S. O. Obare and K. M. Docherty, "Size-Dependent Antimicrobial Effects of Novel Palladium Nanoparticles", PlosOne, vol. 9, no. 1, Jan. 2014, DOI: https://doi.org/10.1371/journal.pone.0085981

[10] L. Xu, D. Liu, D. Chen, H. Liu and J. Yang, "Size and shape controlled synthesis of rhodium nanoparticles", Heliyon, vol. 5, no. 1, Jan. 2019. DOI: https://doi.org/10.1016/j.heliyon.2019.e01165

[11] G. Viau, R. Brayner, L.Poul , N. Chakroune , E. Lacaze, F. F. Vincent and F. Fievet, "Ruthenium Nanoparticles: Size, Shape, and SelfAssemblies", Chemistry of Materials, vol. 15, no. 2, pp. 486 - 494, Dec. 2003. DOI: https://doi.org/10.1021/cm0212109.

[12] L. Qi, H. Colfen and M. Antonietti, "Synthesis and Characterization of CdS Nanoparticles Stabilized by Double-Hydrophilic Block Copolymers", Nano Letters, vol. 1, no. 2, pp. 61-65, Dec. 2001. https://doi.org/10.1021/n10055052

[13] W. Yin, W. Chai, K. Wang, W. Ye, Y. Rui and B. Tang, "Facile synthesis of Sb nanoparticles anchored on reduced graphene oxides as excellent anode materials for lithium-ion batteries", Journal of Alloys and Compounds, vol. 797, pp. 1249-1257, Aug. 2019. https://doi.org/10.1016/j.jallcom.2019.04.329

[14] S. Riaz, N. F. Rana, I Hussain, T Tanweer, A. Nawaz, F Menaa, H. A. Janjua, T. Alam, A Batool, A Naeem, M Hameed, S. M. Ali, "Effect of Flavonoid-Coated Gold Nanoparticles on Bacterial Colonization in Mice Organs" Nanomaterials, vol. 10, no. 9, pp. 1769, July 2020. https://doi.org/10.3390/nano10091769

[15] A. M. E. Shafey, "Green synthesis of metal and metal oxide nanoparticles from plant leaf extracts and their applications: A review" Green Processing and Synthesis, vol. 9, no. 1, pp. 304 - 339, June 2020. https://doi.org/10.1515/gps-2020-0031.

[16] C. Shi, X. Zhang, Y. Sun, M. Yang, K. Song, Z. Zheng, Y. Chen, X. Liu, Z. Jia, R. Dong, L. Cui and X. Xia, "Antimicrobial Activity of Ferulic Acid Against Cronobacter Sakazakii and Possible Mechanism of Action", Foodborne Pathogens and Disease, vol. 13, no. 4, pp.196-204, Apr. 2016. DOI: 10.1089/fpd.2015.1992

[17] H. Zhu, Q. H. Liang, X. G. Xiong, J. Chen, D. Wu, Y. Wang, B. Yang, Y. Zhang, Y. Zhang, and Xi Huang, "Anti-Inflammatory Effects of the Bioactive Compound Ferulic Acid Contained in Oldenlandia diffusa on Collagen-Induced Arthritis in Rats", Evidence-Based Complementary and Alternative Medicine, Volume, May, 2014. Article ID 573801, 10 pages. DOI: 10.1155/2014/573801.

[18] M. Ohnishi, T. Matuo, T. Tsuno, A. Hosoda, E. Nomura, H. Taniguchi, H. Sasaki, H. Morishita, "Antioxidant Activity and Hypoglycemic Effect of Ferulic Acid in STZ-induced Diabetic Mice and KK-Ay Mice”, Biofactors, vol. 21, no. 1-4, pp. 315-319, 2004. DOI: $10.1002 /$ biof.552210161.

[19] E. Latifi, A. A. Mohammadpour, B. Fathi H and H. Nourani, "Antidiabetic and antihyperlipidemic effects of ethanolic Ferula assafoetida oleo-gum-resin extract in streptozotocin-induced diabetic wistar rats", Biomedicine \& Pharmacotherapy, vol. 110, pp. 197202, Feb. 2019. https://doi.org/10.1016/j.biopha.2018.10.152

[20] H. J. Kim, K. Ryu, J. H. Kang, A. J. Choi, Tae-il Kim, J. M. Oh, "Anticancer Activity of Ferulic Acid-Inorganic Nanohybrids Synthesized via Two Different Hybridization Routes, Reconstruction and Exfoliation-Reassembly”, The Scientific World Journal, Article ID 421967, pp. 9, Dec. 2013. https://doi.org/10.1155/2013/421967 
Nanocomposite Formulation of Ferulic Acid with Different Metals Using Computational Method

[21] P. Karak, "Biological activities of flavonoids: an overview" International Journal of Pharmaceutical Sciences and Research, vol. 10 no. 4, pp. 1567-1574. Apr. 2019. https://doi.org/10.13040/IJPSR.0975-8232.10(4).1567-74

[22] M. D Hanwell, D. E. Curtis, D. C.Lonie, T.Vandermeersch, E. Zurek and G. R. Hutchison "Avogadro: an advanced semantic chemical editor, visualization, and analysis platform" 2012.. Journal of Cheminformatics. 4: pp. 17.

[23] H. Y. Wang, Y. F. Li, C. Z. Huang, "Detection of Ferulic Acid Based on the Plasmon Resonance Light Scattering of Silver Nanoparticles", Talanta, vol. 72 no. 5, pp. 1698-703. Jul. 2007. DOI: 10.1016/j.talanta.2007.02.028.

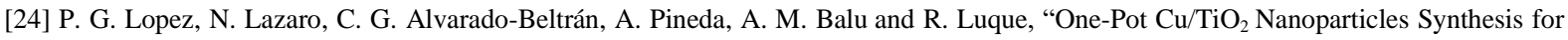
Trans-Ferulic Acid Conversion into Vanillin", Molecules, vol. 24, no. 21, pp 3985, 2019. https://doi.org/10.3390/molecules24213985.

[25] A. E. Angkawijaya, A. E. Fazary, E. Hernowo, M. Taha and Y. H. Ju, "Iron (III), Chromium (III), and Copper (II) Complexes of LNorvaline and Ferulic Acid", Journal of Chemical \& Engineering Data, vol. 56, no. 3, pp. 532-540, Feb. 2011. DOI: https://doi.org/10.1021/je101075q

[26] E. P. Babu, A. Subastri, A. Suyavaran, K. Premkumar, V. Sujatha, B. Aristatile, Ghedeir M. Alshammari, V. Dharuman and C. Thirunavukkarasu "Size Dependent Uptake and Hemolytic Effect of Zinc Oxide Nanoparticles on Erythrocytes and Biomedical Potential of ZnO-Ferulic acid Conjugates", Scientific Reports, vol. 7, Jun. 2017. Article number: 4203. DOI: https://doi.org/10.1038/s41598-017-04440-y

[27] M. Ramezanpour, S. S. W. Leung, K. H. Delgado-Magnero, B. Y. M. Bashe, J. Thewalt, D.P. Tieleman, "Computational and experimental approaches for investigating nanoparticle-based drug delivery systems”, Biochimica et Biophysica Acta (BBA) - Biomembranes, vol. 1858, no. 7, July 2016, pp. 1688 - 1709. https://doi.org/10.1016/j.bbamem.2016.02.028

\section{Publish your research article in AlJR journals- \\ $\checkmark \quad$ Online Submission and Tracking \\ $\checkmark$ Peer-Reviewed \\ $\checkmark$ Rapid decision \\ $\checkmark \quad$ Immediate Publication after acceptance \\ $\checkmark \quad$ Articles freely available online \\ $\checkmark \quad$ Retain full copyright of your article. \\ Submit your article at journals.aijr.in}

\section{Publish your books with AIJR publisher-}

$\checkmark \quad$ Publish with ISBN and DOI.

$\checkmark \quad$ Publish Thesis/Dissertation as Monograph.

$\checkmark \quad$ Publish Book Monograph.

$\checkmark$ Publish Edited Volume/ Book.

$\checkmark \quad$ Publish Conference Proceedings

$\checkmark \quad$ Retain full copyright of your books.

Submit your manuscript at books.aijr.org 